\title{
Pragmatic and Grammatical Awareness in IELTS Speaking Part 3
}

\section{Danial Babajani Azizi ${ }^{1 *}$, Mehrshad Ahmadian², \& Fatemeh Miri ${ }^{3}$}

\footnotetext{
* Correspondence:

danialbabajani@yahoo.com

1. Department of English Language,

Khazar Institute of Higher Education,

Mahmoud Abad, Iran

2. Department of English Language,

Islamic Azad University of Qaemshahr,

Qaemshahr, Iran

3. Department of English Language,

Islamic Azad University of Bushehr,

Bushehr, Iran
}

Received: 2 February 2020

Revision: 2 May 2020

Accepted: 8 June 2020

Published online: 20 June 2020

\begin{abstract}
Although discrete research on pragmatic and grammatical awareness is wellvisited in second language acquisition, the exploration and assessment of these two variables in tandem in standardized language proficiency tests has not garnered thick literature. On this ground, this study attempted to examine the correlation of both pragmatic and grammatical awareness with IELTS speaking Part 3. To this end, 120 homogenized Uzbek IELTS-taken applicants were asked to fill out pragmatic and grammatical awareness questionnaire adopted from Albertson (2011) followed by IELTS speaking Part 3 administration in order to obtain a correlation between pragmatic awareness and IELTS speaking Part 3 as well as grammatical awareness and IELTS speaking Part 3, respectively. The results of data analyses via running Pearson correlation coefficient indicated that both pragmatic awareness and grammatical awareness were significantly correlated with IELTS speaking Part 3. The findings imply that building on these two types of awareness would probably help learners increase their performance on IELTS speaking Part 3. Additionally, the students' awareness-raising on pragmatic aspect of language in IELTS speaking Part 3 upon which interaction is based could probably convince the examiners on IELTS speaking venues that they are fully aware of pragmatic items and their conveyed message would not be misunderstood.
\end{abstract}

Keywords: Pragmatic awareness, grammatical awareness, IELTS Speaking Part 3. 


\section{Introduction}

Pragmatic awareness is the information of how to use language for social-meaning encoding via conscious contemplation of association among parameters engaged in pragmatic comprehension and production (Takahashi, 2013). Pragmatic awareness is of two types: pragmalinguistic awareness and sociopragmatic awareness. Pragmalinguistic awareness is the analyzed knowledge of the association between form and function related to specific sociocultural contexts. For example, if an individual knows that an interrogative form is used when s/he wants to address his/her interlocutor's function as a request, s/he demonstrates his/her pragmalinguistic awareness of one type of request. Sociopragmatic awareness is the analyzed knowledge of the association between communicative action and contextual parameters. Contextual parameters consist of social status, social distance, and communicative action giving rise to imposition. For example, it would represent sociopragmatic awareness in case an individual knows that a specific culture has more proclivity to correcting arguments made by higher-status individual in indirect way than equal-status or low-status (Takahashi, 2013). Pragmatic awareness is a receptive ability which is defined here as which expressions, language registers, and vocabulary are propitious in terms of social situations (Albertson, 2011). The term pragmatic competence involves awareness as well as the ability of such language in a pragmatic way on its own right.

Speaking is a productive oral skill and is one of the most difficult skills out of concern with its occurrence in real world (Nunan, 2003). According to Askari and Langroudi (2014), speaking consists of productive verbal utterances so that meaning could be put across. Spoken language is auditory and vanishing. The objective of speaking is that the receiver can understand the utterance produced. Speaking, on account of its complex involvement in meaningconstruction, is known as one of the difficult skills among other skills (Celce-Murcia, \& Olshtain, 2000). Shohamy (2015) asserts that speaking skill is practiced in face-to-face conversational situations and performance is evaluated in terms of ability to use and function in language. It is not evaluated only on the basis of knowing systems of language. She goes on maintaining that the chief benefit of oral interview is that speaking takes place in real-world situation in which the testee is required to use language in a communicative/conversational situation. She adds that the primary benefit of oral interview is in the realm of practicality; the expense of manpower, administration, and grading is very high.

Furthermore, a domain to which little attention is paid in the past is the inextricable interconnection of pragmatic and grammatical awareness (Schauer, 2006). Grammar associates with structure accuracy, consisting of syntax and morphology (Bardovi-Harlig \& Dornyei, 1998). Andrews (1999) mentions that grammatical awareness is of four types: a) Type 1: ability of metalanguage recognition, b) Type 2: ability of appropriate metalanguage terms production, c) Type 3: ability of error correction and identification, and d) Type 4: ability of grammatical rules explanation. Each of them puts focus on different modes of explicit knowledge of grammar and grammatical terminology. The first one deals with recognizing such grammatical categories as preposition, noun, and verbs. The second one deals with appropriate metalinguistic terms production containing the ability of grammatical terms of a given word/phrase provision. The third one deals with identifying and creating error which contains the ability of identification and correction of erroneous sentences or parts of sentences. The last type deals with grammatical rules explanation which has been broken.

\subsection{Statement of the Problem}

Existing research with regard to adult foreign or second language learners' pragmatic competence indicated that improvement of grammar does not assure pragmatic development. Even advanced learners may be unable to produce or comprehend the intended message so that they could adopt target-like manifestation of pragmatics, and advanced learners take it into consideration how pragmatic features could be manifested by the target language (Bardovi-Harlig \& Dornyei, 1997). Research literature in the domain of pragmatics has detected a number of ways in which learners' target language was different from that of native speakers (Bardovi-Harlig, 2001).

Furthermore, as demonstrated by some studies, there is hardly a mutual interplay between grammatical and pragmatic development. It is even sometimes the case that learners with significant grammatical competence show significant pragmatic competence in conversation; even more than native speakers (Bardovi-Harlig \& Hartford, 1990, 1991, 1993; Omar, 1991, 1992). Grammatical awareness has been the focus of study within second language acquisition (SLA) for some time, but on account of space limitations it is not possible to discuss this in details (Bardovi-Harlig, 2000). 
Finally, and the following the introduction of the concept of pragmatic competence, the evaluation of pragmatic knowledge has become the main goal of most standard language proficiency tests in general and International English Language Testing System (IELTS) in particular. However, only a very small number of studies have examined the pragmatic and grammatical awareness of second or foreign language learners in an integrated paradigm. As such, the present study aimed to make effort to bridge the gap in the literature by probing into the pragmatic and grammatical awareness assessed in speaking Part 3 of IELTS entitled discussion. Although so many existing studies were undertaken with regard to pragmatic awareness on the one hand, and on proficiency tests on the other hand, such a study, to the best of the current researchers' knowledge, seems to have not been conducted to test IELTS candidates' pragmatic and grammatical awareness in speaking Part 3. The findings of the current study may alert all three testdeveloping, test-coaching, and test-taking groups to pay due attention to this facet of language proficiency assessment.

\subsection{Research Questions}

Is there any statistically significant relationship between pragmatic awareness and IELTS speaking Part 3 ?

Is there any statistically significant relationship between grammatical awareness and IELTS speaking Part 3 ?

\subsection{Research Hypotheses}

1. There is no statistically significant relationship between pragmatic awareness and IELTS speaking Part 3.

2. There is no statistically significant relationship between grammatical awareness and IELTS speaking Part 3.

\section{Review of the Literature}

\subsection{Theoretical Framework}

\subsubsection{Pragmatic Competence}

Having the ability to use language rather than knowledge of the system of language is totally accepted in the field of language learning. Chomsky (1965) differentiated between linguistic performance, or manifestation of language use, and linguistic competence comprising underlying knowledge of language. Learner should make efforts to be proficient in both area from the language learning viewpoint. Moreover, in order to be socially proficient in a language, learners need to possess communicative competence or the knowledge that when specific forms and vocabulary are acceptable and appropriate in a language grammatically and sociolinguistically (Hymes, 1972). A learner might produce a correct grammatical sentence but may not possess communicative competence and end up in socially awkward communication. Thomas (1983) regards such situations as 'pragmatic failure' which yields negative transfer stemming from native language. Other cases of pragmatic failure might be of tremendous seriousness and blow to the learnerinterlocutor relationship because the learner may unconsciously convey a message leading to taking him or her impolite or direct into account. Pragmatic competence, as Thomas argues, entails the knowledge if something is acceptable in a context or not while grammatical competence is decontextualized and abstract.

According to Jung (2001), an individual can be pragmatically competent language user who possesses the following characteristics:

1) The Ability to Perform Speech Acts: speech act was devised by Austin (1962) and later more enlarged by Searle (1969). A few years later in 1969, Austin has more worked on speech acts and bestowed more efficiency on it. He then categorized them into five subsets of Declaratives, Representatives or Assertives, Expressives, Directives, and Commissives (Yule, 2000).

2) The Ability to Convey and Interpret Non-literal Meanings: This ability is directly associated with Grice's cooperative principles and meaning of implicature as well.

3) The Ability to Perform Politeness Strategies: According to Holmes (2008), politeness is a complex task which involves knowing the language and sociocultural values of the community. She also mentions that "generally speaking politeness involves taking into account the feeling of others." (p. 281). According to chief studies on politeness (Brown \& Levinson, 1987; Lakoff, 1973; Leech, 1983), linguistic expressions differ in degree if politeness. 
4) The Ability to Carry out Discourse Functions: Since a few decades, linguists found out that sentence is not the sole criterion of communication and examination of language and language learning should go beyond sentence to from texts which is called as discourse. "The connections between sentences are called cohesive relations" (Yule \& Brown, 1989, p. 191). Different parts of text are interconnected although they differ in various forms. Even though in some cases there exists linguistic elements realizing the association between facts and cohesion, sometimes in some cases the underlying semantic association between sentences and propositions have cohesive power and coherence.

5) Cultural Knowledge: Culture is what people "must know in order to act as they do, make the things they make, and interpret their experience in the distinctive way they do" (Quinn \& Holland, 1987, p. 4). According to Bloch (1991), culture is defined as what human beings are required to get familiar with so that they could materialize it reasonably and efficiently in social environment. Social environment includes social organizations and behaviors. "A society's culture consists of whatever one has to know or believes in order to operate in a manner acceptable to its members, and to do so in any role that they accept for anyone of themselves" (Goodenough, 1957, p. 167). So, cultural knowledge is "socially acquired: the necessary behaviors are learned and do not come from any kind of genetic endowment" (Wardhaugh, 2008, p. 216).

\subsubsection{Pragmatic Awareness}

As noted by Schauer (2006) comparative studies of pragmatics conducted 20 years ago were of extreme significance for the purpose of establishment in finding production and comprehension differences of contextually appropriate speech. The majority of theories with respect to pragmatics are framed in awareness and noticing inaugurated by Schmidt (1995). Given the range of learning from explicit to implicit or vice versa, the treatments greatly vary along a continuum of how likely learners notice the input (Rose \& Kwai-Fun, 2001; Rose \& Ng, 2001; Takahashi, 2001). A literature review in the arena of interlanguage pragmatics displays that miscellaneous individual variables comprising motivation (Takahashi, 2005), language proficiency (Matsumura, 2003; Takahashi, 2005), learning environment (Matsumura, 2001; Schauer, 2006), target language exposure (Matsumura, 2003), length of residence in target language country (Bella, 2012), and emotional intelligence (Rafieyan, et. al., 2014) on the development of pragmatic awareness are largely influenced by the research undertaken on pragmatic awareness.

\subsubsection{Grammatical Awareness}

Language awareness, has been considerably discussed by specialists Al-Hejin (2005), Kennedy (2012), Rezaei and Hosseinpur (2011), Schmidt (2012), and Svalberg (2007), played part in SLA. The scholars asserted that language awareness is raison d'être of noticing to target language structure. Therefore, language awareness is prerequisite to noticing the target language structure. Our minds seem robust, so the researchers of the current study strongly believe that given grammatical awareness is raison d'être of language learners' interlanguage, they will remember the errors committed and feedback delivered. Being grammatically competent and aware, learners will avoid utilizing erroneous structures and will recall feedback, respectively. This sort of awareness is language knowledge and grammar is one dimension of language. "Language knowledge is what is in the mind of language users, and when they use it appropriately to achieve their communicative purpose in a given context, they exhibit their language ability" (Kumaravalivelu, 2006, p. 21). Hence, the more competence, the more awareness. The notion could be largely pertinent to explicit and implicit knowledge in Doughty's term (2003). It is this that being grammatically aware varies along a continuum of explicit and implicit that explicitly knowing the rules may belate to display the ability since it requires probing consciously into the rules to (re)structure the language knowledge in general and grammatical knowledge in particular. On the other hand, the language user will promptly process the competence in mind to turn it into output.

\subsubsection{IELTS Speaking Part 3}

Having the Cue Card done, which is the second part of the speaking test, the examiner will move on and ask examinee some broad follow-up questions. "The examiner will invite you to discuss a number of issues, broadly related in theme to the Part 2. The questions will increase in difficulty slightly as this part of the test progresses" (Memarzadeh, 2008, p. 134). This part comes under the titles of discussion, two-way discussion, follow-up questions, and details discussion which is designed to give examinees the opportunity to talk about more abstract issues and ideas. The questions require the testees to expand their answers further with explanation and examples of the world in general and the examiner strictly controls the time. 


\subsection{Related Studies}

Bardovi-Harlig and Griffin (2005) in a study reported the results of a pragmatic awareness in an English as a second language (ESL) class before delivering formal instruction in pragmatics. Learners worked in pair during the activity in order to detect pragmatic shortcomings in video-taped and played short roles to obviate the detected inadequacies. Even though form and content of modifications were different from target-like norms in some dimensions, the role plays demonstrated that learners realized and filled the missing speech acts and semantic formulas as well. Consequently, findings of the activity offer suggestions for areas in which learners might make use of instruction. Albertson (2011) studied firstly how the social network Facebook (FB) associates with pragmatic and grammatical awareness and secondly examined how leaners utilize FB. Findings showed there was not a significant correlation between pragmatic awareness and native speakers (NS) contact whereas grammatical awareness had a partially strong correlation with native speaker contact delivered to them via FB. Not only positive but also negative effects were found on subjects' learning of grammatical form on the part of NSs and non-native speakers (NNSs) among FB conversations.

Rafeiyan, Sharafi-Nejad and Eng (2014) in an intensive English program conducted a study on 60 English learners at Universiti Sains Malaysia. A contextualized pragmatic judgment task, a multiple choice test of pragmatic listening comprehension, and an oral discourse completion task assessed pragmatic awareness, comprehension, and production, respectively. The findings of Pearson-product moment correlation coefficient demonstrated that pragmatic features of target language are prognosticator of conducive comprehension and production which are conventional in target language. Pedagogical implications of the results of the study offered suggestions for English as a foreign language (EFL) learners' target language awareness development of pragmatic features.

In another study, Allami and Aghajari (2014) aimed to assess the degree of pragmatic knowledge in IELTS listening Task 1. The component of pragmatic knowledge assessed in their study was on the basis of Bachman's (1991) model and developed by Jung (2002). Moreover, they showed the component of pragmatic competence which was unequally assessed. Karbalaei and Rahmanzade (2015) placed their emphasis on analyzing listening sections of such international proficiency tests as IELTS and Test of English as a Foreign Language (TOEFL) tests and the local test like Test of Language by the Iranian Measurement Organization (TOLIMO) from pragmatic standpoint. Findings of the research revealed that TOLIMO, TOEFL, and IELTS could assess testees' pragmatic knowledge however more instances of pragmatic knowledge component included in TOEFL and TOLIMO.

Juul (2005) in a study entitled "grammatical awareness and the spelling of inflectional morphemes in Danish" examined Danish sixth-graders. They were asked to spell word consisting of inconsistent but grammatically unique inflectional endings such as present verbs and present participles. The study demonstrated that as measured via an 'odd word out', both types of inflections' scores had correlation with grammatical awareness despite the unsatisfactory correlation which signifies that grammatical awareness is relevant to inflectional spelling competence. Hou and NaThalang (2013) examined the role-play of grammar awareness in Chinese EFL learners' learning English of whmovement. Grammaticality judgment tests (GJT) was administered to eighty adult native Chinese speakers to get to know whether or not they are restrained by wh-in-situ parameters. As within-group and between-group comparisons ran, it gave indication that improvement occurred in second language learners' performance in judging the grammaticality of the wh-movement when they were aware of the target linguistic phenomenon. The conclusion was that there was a positive relationship between grammar awareness in learning English wh-movement with testees' performance on GJT.

Jahan and Kormos (2015) studied the effect of textual enhancement on English language learners' noticing of and grammatical awareness of expressing future plans and intentions. The results indicated that both the development of metalinguistic knowledge of the 'be going to' production and controlled use of the production of 'will' for future plans and intentions are facilitated via textual enhancement of input. However, the sole input enhancement was not efficacious to contribute the participants in acquiring full understanding of form-to-function mappings complexities regarding the targeted future meanings. In their study entitled EFL learners' grammatical awareness through accumulating formulaic sequences of morphological structure (-ing), Kashiwagi and Ito (2017) explored the degree to which Japanese understudies who had finished 150 hours of English exercises (age 13, N = 95) saw semantic themes 
when utilizing a linguistic judgment test. Focusing on the present dynamic shape -ing as formulaic sequence, the instructor utilized three medicines: (a) review of piecing, (b) organized info and dictogloss, and (c) a ten-minute inductive explanation of language in L1. The outcomes uncovered huge contrasts among pre-and post-tests for ungainliness of word arrange $(31 \%<59 \%)$ and exclusion of morphemes: -ing $(61 \%<74 \%)$. By and large, understudies who had gotten the instructional medium displayed syntactic affectability to predictable succession.

Finally, the present study did its best to fill the gap in the existing literature by exploring the relationship between both pragmatic and grammatical awareness, on the one hand, and IELTS speaking part 3, on the other hand, in an attempt to see whether a high score on the speaking part 3 could only be regarded as an indicator of linguistic (grammatical) competence of examinees, or it could suggest some degrees of pragmatic awareness of the test-takers as well.

\section{Methodology}

\subsection{Design of the Study}

As mentioned earlier, the present study aimed at finding the relationship between pragmatic awareness and IELTS speaking Part 3 as well as grammatical awareness and IELTS speaking Part 3. On account of the existence of a single group in the current study, the design is correlational.

\subsection{Participants}

The researchers of the current study selected two classes of advanced level, each of which consisted of 60 students. A total of 120 Uzbek IELTS-taken students who were also undergraduate EFL University students majoring in Teaching English to Speakers of Other Languages (TESOL) have participated in this study, including 68 females along with 52 males. Participants were selected from a university in Tashkent, Uzbekistan. All participants have taken International English Language Testing service (IELTS) test, and all of them were studying English as an academic major. The age of participants ranged 21-24. As non-English major university students do not develop functional English proficiency, they are not usually provided with chance to speak English as much as English major students, and their English class is confined to reading and vocabulary, the authors did not select them. It is worth noting that the participants' consent was obtained to take part in the research so as to satisfy the ethical considerations.

\subsection{Instruments}

\subsubsection{Oxford Placement Test}

150 university students were the population of the present study. Having administered Oxford Placement Test (OPT), 120 participants were elicited from 150 students as a sample of the study via obtaining the score ranging from 47 to 58 as this continuum of scores is regarded as advanced level of proficiency as its guideline orders. The OPT was primarily utilized in order to measure and determine the participants' level of general English language proficiency and to ensure their homogeneity. The OPT is often used by English Language Teaching (ELT) researchers as a language proficiency test in which participants' level will be determined based on the guideline of the test and the scores students obtain. This test consists of 60 items in the form of multiple choice questions, and students were supposed to select the correct answer from among the alternatives. The required time to complete the test is 30 minutes. The reliability of the OPT was also checked in the present study on the part of the researchers and the Cronbach Alpha yielded a .93 value indicating a high reliability index.

\subsubsection{Test of Pragmatic/Grammatical Awareness}

Test of pragmatic/grammatical awareness adopted from Albertson (2011) is utilized to collect data with regard to pragmatic/grammatical awareness in this study. In order to gear the questionnaire to the aim of the present study, it was piloted to 20 students majoring in English as an academic major who have sat for IELTS to ensure its reliability and comprehensibility of items. In order to check the validity of the questionnaire, a panel of experts, who were university instructors, were asked to evaluate the questionnaire. The panel provided positive feedback with respect to the validity of the scale and then it was utilized. The reliability value obtained in this phase was .71. To improve the reliability, the questionnaire was reviewed by experienced experts working on pragmatics, based on their comments, no nebulous items were found. Reliability of the questionnaire was calculated via running Cronbach Alpha formula turned out to be .71 which according to Pallant (2013), is acceptable. The instrument consists of 25 items and each item is divided into two parts; an item associated with grammatical awareness including dichotomous yes-no response and another one associated with pragmatic awareness as Likert scale which includes 5 ordinal options from Not bad 
at all to Very bad. It is worth mentioning that the instrument has provided the testees with an instruction in conjunction with an example so as to obviate the obfuscation of how to make response to the items. Moreover, the time taken to fill out the aforementioned instrument on the part of the participants was about 20 minutes.

\subsubsection{IELTS Speaking Part 3}

As IELTS Speaking Part 3 entitled discussion involving nine questions is one of the variables of the study, the researchers assigned the task of its administration and scoring to a real IELTS Examiner as a reliable source of administering and scoring, respectively. However, he asked 5 questions to the participants as the other real IELTS Examiners normally ask 4 to 6 questions on IELTS venues. The time taken to administer IELTS Speaking Part 3 was 5 minutes.

\subsection{Data Collection}

Initially, the researchers asked an Uzbek instructor who was a PhD holder of TESOL at a university in Uzbekistan to request her students whether or not they were prepared to take part in the research as participants. An A to Z of research process was told to them so that they may make sure of their participation and their consent was also obtained so as to meet the ethical considerations. Next, the 150 potential participants were administered OPT in order to guarantee their homogeneity. Having administered the OPT, 120 participants were extracted from the whole population which was 150. Then, the researchers provided the instructor with the online pragmatic/grammatical awareness test to forward it to the participants to fill it out. Ultimately, the researchers built rapport with a real IELTS Examiner as an individual professionally knowing the rope of IELTS in the same country who was accessible to the participants. The IELTS examiner was asked to administer IELTS Speaking Part 3 entitled discussion along with the scoring. He administered the third part of speaking in five minutes consisting of five questions and then he himself scored them.

\subsection{Data Analysis}

In this correlational study, the data are garnered form one group were analyzed running Pearson correlation for both research questions; however, test of normality is run before gaining such a correlation coefficient in order to guarantee the data normality using SPSS software 16. As the data were normally distributed, parametric test of Pearson correlation is utilized, otherwise Spearman correlation as nonparametric test corresponding Pearson correlation would be employed.

\section{Results}

The results are separately shown for the scores on pragmatic and grammatical awareness as well as IELTS speaking Part 3. In order to decide on the type of tests to use for analyses, the normality of the obtained data had to be determined. Hence, normality of the data obtained from IELTS speaking Part 3 was checked to show whether or not the data are normally distributed.

Table 1 . The test of normality for the IELTS speaking part 3

\begin{tabular}{|c|c|c|c|c|c|c|}
\hline & \multicolumn{3}{|c|}{ Kolmogorov-Smirnova } & \multicolumn{3}{|c|}{ Shapiro-Wilk } \\
\hline & Statistic & df & Sig. & Statistic & $\mathrm{df}$ & Sig. \\
\hline IELTSSpeak3 & .173 & 120 & 0.56 & .928 & 120 & .065 \\
\hline
\end{tabular}

As they are shown in the above table, the values of $\mathrm{P}$ for both Kolmogorov-Smirnov and Shapiro-Wilk tests of normality for the total results of the data were found to be larger than .05. This meant that the data did show normal distribution.

\subsection{Research Question 1}

Is there any statistically significant relationship between pragmatic awareness and IELTS speaking Part 3 ?

The normality of data on pragmatic awareness is also checked to explore if normal distribution took place or not.

Table 2. The test of normality for the pragmatic awareness 


\begin{tabular}{|c|c|c|c|c|c|c|}
\hline & \multicolumn{3}{|c|}{ Kolmogorov-Smirnov } & \multicolumn{3}{|c|}{ Shapiro-Wilk } \\
\hline & Statistic & $\mathrm{df}$ & Sig. & Statistic & df & Sig. \\
\hline PragmAware & .109 & 120 & 0.155 & .966 & 120 & 0.615 \\
\hline
\end{tabular}

As they are shown in the above table, the value of $\mathrm{P}$ for both Kolmogorov-Smirnov and Shapiro-Wilk tests of normality on the data of pragmatic awareness were found to be larger than .05 . It shows that the data are normally distributed, and as such, one of the assumptions for the use of parametric test is met. Thus, parametric test is run to analyze the total result of pragmatic awareness. To check the correlation between pragmatic awareness and IELTS speaking Part 3, and having assured the data are normally distributed, Pearson Correlation coefficient is employed. The following tables demonstrate both descriptive statistics and statistical test of Pearson correlation between pragmatic awareness and IELTS speaking Part 3.

Table 3. Descriptive statistics for IELTS speaking part 3 and pragmatic awareness

\begin{tabular}{llll}
\hline & Mean & Std. Deviation & N \\
\hline IELTSSpeak3 & 6.12 & .70631 & 120 \\
\hline PragmAware & 80.73 & 7.74785 & 120 \\
\hline
\end{tabular}

Table 4: Pearson correlation of IELTS speaking part 3 and pragmatic awareness

\begin{tabular}{llll}
\hline & & IELTSSpeak3 & PragmAware \\
\hline IELTSSpeak3 & Pearson Correlation & 1 & $.76^{* *}$ \\
\cline { 2 - 4 } & Sig. (2-tailed) & .000 \\
\cline { 2 - 4 } & $\mathrm{N}$ & 120 & 120 \\
\hline PragmAware & Pearson Correlation & $.76^{* *}$ & 1 \\
\cline { 2 - 4 } & Sig. (2-tailed) & .000 & 120 \\
\cline { 2 - 3 } & $\mathrm{N}$ & 120 & \\
\hline
\end{tabular}

According to the above table, the correlation coefficient of IELTS Speaking Part 3 and pragmatic awareness was .76 at significance value of $\mathrm{P}<.01$. The result shows that there is a highly significant correlation between IELTS speaking Part 3 and pragmatic awareness.

\subsection{Research Question 2}

Is there any statistically significant relationship between grammatical awareness and IELTS speaking Part 3 ?

The normality of data on grammatical awareness is also checked to find out whether or not the data are normally distributed.

Table 5. The test of normality for the grammatical awareness

\begin{tabular}{|c|c|c|c|c|c|c|}
\hline & \multicolumn{3}{|c|}{ Kolmogorov-Smirnov ${ }^{\mathrm{a}}$} & \multicolumn{3}{|c|}{ Shapiro-Wilk } \\
\hline & Statistic & df & Sig. & Statistic & df & Sig. \\
\hline GramAware & .170 & 120 & 0.130 & .950 & 120 & 0.315 \\
\hline
\end{tabular}


As they are exhibited in the table above, the data are checked via running both tests of normality; that is, KolmogorovSmirnov and Shapiro-Wilk showing the data are found to be larger than .05. It conveys the meaning that the data did show normal distribution, and as such, one of the conditions to run parametric test is established. Hence, parametric test is utilized to conduct analysis of total result of grammatical awareness. In order to check the correlation between grammatical awareness and IELTS speaking Part 3 and making sure of normal distribution of the data, Pearson Correlation coefficient is run. The following tables indicate both descriptive statistics and statistical test of Pearson correlation between grammatical awareness and IELTS speaking Part 3.

Table 6. Descriptive statistics for IELTS speaking part 3 and grammatical awareness

\begin{tabular}{llll}
\hline & Mean & Std. Deviation & $\mathrm{N}$ \\
\hline IELTSSpeak3 & 6.12 & .70631 & 120 \\
\hline GramAware & 13.97 & 1.93131 & 120 \\
\hline
\end{tabular}

Table 7. Pearson correlation of IELTS speaking part 3 and grammatical awareness

\begin{tabular}{llll}
\hline & & IELTSSpeak3 & GramAware \\
\hline IELTSSpeak3 & Pearson Correlation & 1 & $.58^{* *}$ \\
& Sig. (2-tailed) & .000 \\
\cline { 2 - 4 } & $\mathrm{N}$ & 120 & 120 \\
\hline GramAware & Pearson Correlation & $.58^{* *}$ & 1 \\
\cline { 2 - 4 } & Sig. (2-tailed) & .000 & 120 \\
\cline { 2 - 3 } & $\mathrm{N}$ & 120 & 120 \\
\hline
\end{tabular}

According to the above Table, the correlation coefficient of IELTS Speaking Part 3 and grammatical awareness was .58 at significance value of $\mathrm{P}<.01$. The result shows that there is a highly significant correlation between IELTS speaking Part 3 and grammatical awareness.

\section{Discussion}

The present study aimed at exploring pragmatic and grammatical awareness in the light of IELTS speaking Part 3. The results of data analysis as to the first research question showed that pragmatic awareness and IELTS speaking Part 3 are significantly correlated with each other. This finding is in line with those of Rafieyan, Sharafi-Nejad, and Eng (2014) who reported that "awareness of target language pragmatic features is a predictor of appropriate comprehension and production of target language conventional expressions" (p. 1352). This finding may be interpreted in the light of prefabricated patterns or conventional expressions whose uses are delineated in appropriate contexts. This study is also in contrast to those of Bardovi-Harlig and Dornyei (1998) in the Hungarian sample, people who had spent some time abroad or had had native-English-speaking teachers did not score higher on the grammatical and pragmatic items. In other words, among this group of learners, limited contact with native speakers did not significantly influence their responses (253).

It can be claimed that the sample of the current study was Uzbek who had spent intensive time of studying English. Put it in another way, they were both majoring in TESOL and engaged in IELTS that their analyzed knowledge specifically in IELTS to acquire in an attempt an ideal score was galvanized to put their focus intensively on pragmatic and grammatical items since lack of awareness in these two domains would decrease the score on such a test; therefore, presence in English-speaking environment cannot be a rationale to increase pragmatic and grammatical awareness in a short period of time but what is of tremendous importance is intensive working on English to gain explicit knowledge of pragmatic and grammatical items. The claim is advocated by the above authors in the same work that learners' outperformance is dependent upon their contact with English in academic setting. 
Lee (2009) stated that "EFL learners may have the learnability to develop their pragmatic awareness" (p. 631). This finding is associated with Schmidt's (2001) theory named "noticing hypothesis" proposing that heeding to things, people will learn them and not heeding to things, people will not learn them. Schauer (2006) in his study found that Germans in ESL context identified more pragmatic errors in early stages than those of professional learners in EFL context. It shows that his study is incongruent with the current study that the participants in this study were pragmatically aware of English language system implicating that being pragmatically aware of English language system is contingent upon the context wherein the individuals are in contact with. Learners' curricula supply them with inadequate appreciation of pragmatic items and dearth of exposure to L2 out of class setting. Apparently, English is taught as foreign language in Uzbekistan and the learners are not provided to have sufficient opportunity to utilize it aptly and their availability is only confined to what the curriculum proposes (Schauer, 2006).

As Bardovi-Harlig and Dornyei (1998) put, bogwash effect of language tests impacts on different performance of EFL and ESL learners' sensitivity to grammatical and pragmatic complications. The present study claims that as the participants of the study were IELTS-taken students and have experienced such problems while taking the test, this experience had impact on their performance to be cognizant of pragmatic as well as grammatical items. Furthermore, coaching can be taken into account in this regard; that is to say, the participants who are potential IELTS instructors may teach their pupils to be pragmatically aware then test it via summative assessment in the classrooms to see how far they have made progress or via formative assessment to be in the process of their awareness plus shaping their competencies and skills so as to help them continue their growth.

Pragmatic awareness does not necessarily result in pragmatic competence since other researchers have found that awareness is not the sole criterion in SLA (Robinson, 1997; Schmidt, 1993, 1995). The participants of this study were of highly aware of pragmatic items as their proficiency level of English knowledge was high. In other words, the higher proficiency levels, the higher pragmatic awareness since they comparatively know the rope of English language system and have sufficient recognition to it. Previous literature demonstrated that higher proficiency level has correlation with higher level of pragmatic awareness (Cook \& Liddicoat, 2002; Rafieyan, Sharafi-Nejad, \& Eng, 2014). Pragmatic infelicities are more serious than grammatical errors because error in pragmatic items would get the message misunderstood but grammatical errors is not so; that is, grammatical errors would not put across the message misleadingly. However, errors in either would ruin the utterance both pragmatically and syntactically.

According to Sorour (2015), the absence of pragmatic competence is one of the chief origins of communication failures that may take place between proficient speakers and learners of a language. Schauer (2006) indicated that "the vast majority of the learners in England and the English native speakers perceived pragmatic errors to be more serious than the grammatical ones" (309). Propitious heeding to the use of utterances of the target language was provided as the language learners were pragmatically aware of the discrepancies between mother-tongue and target language. The finding related to the first research questions acquired through this study is congruent with findings gained through the study carried out by Taguchi (2011) who explored that the experience of studying abroad had impact on comprehension and conventional expressions. The congruence is also directed to the study undertaken by Rafieyan, Sharafi-Nejad, and Eng (2014, p. 1352) "revealed that awareness of target language pragmatic features is a predictor of appropriate comprehension and production of target language conventional expressions." The significant correlation between pragmatic awareness and IELTS speaking Part 3 could be attributed to this point that taking English as the learners' academic major together with their engagement in IELTS provides a case of additive bilingualism, the more recognition of two language differences, the more pragmatic awareness will yield.

The results of data analysis as to the second research question showed that grammatical awareness and IELTS speaking Part 3 are significantly correlated with each other. This finding is in agreement with Hou and Na-Thalang's (2013) research reporting that there was a positive correlation between grammar awareness in learning English wh-movement and subjects' performance in grammaticality judgment tests. As the participants of the present study were exposed to enhanced input namely both in IELTS environment and at university, the chances of getting aware of grammaticality increased. Jahan and Kormos (2015) maintained that manifold contact with enhanced input would rise the learners' chances of noticing the targeted forms. This might lead to achievements in procedural knowledge with respect to grammar as they are engaged in two rounds of language learning which was operationalized in IELTS speaking Part 3. With regard to the immersion in two settings of English language learning, the learners could make development in grammatical awareness. Another possible explanation of the correlation between grammatical awareness and IELTS speaking Part 3 would be the participants' prior knowledge of grammar directed the participants to take advantage of their awareness. It seems to be in accord with Kirschner, Sweller, and Clark (2006) noting that nominally guided 
instruction might be more beneficial for students who have pre-existing knowledge in the field shaping the focus of study.

The relationship between grammatical awareness and IELTS speaking Part 3 may reflect that both of these two variables required the participants to take semantic and syntax into account so as to detect grammatically and pragmatically correct sentences. Not only do the participants in the current study encounter the challenge of producing correct grammatical sentences but also of learning foreign languages. It appears likely that both of these challenges will be difficult for participants having extreme sensitivity to grammaticality since such a shortcoming would result in reducing score in IELTS speaking module. This finding recommends that betterment in performance on grammatical awareness advocates the performance on IELTS Speaking Part 3. There have been a positive correlation between grammatical awareness and IELTS speaking Part 3 and stimulation of the former one seems to boost the performance on the latter on. The grammatical awareness in this study appears to have enhanced morpho-syntactic aspect making deliberate control over the language.

\section{Conclusion}

The results of the study showed that both pragmatic and grammatical awareness are significantly correlated with IELTS speaking Part 3. It also indicated that building on these awareness would probably help learners increase their performance on IELTS speaking Part 3. Hence, it also advocated Schmidt's (2001) Noticing Hypothesis maintain that noticing is a prerequisite to further language development. Additionally, the students' awareness-raising on pragmatic aspect of language in general and IELTS speaking Part 3 in particular upon which interaction is based could probably convince the examiners on IELTS speaking venues that they are fully aware of pragmatic items and their conveyed message would not be misunderstood. Moreover, the students' awareness-raising on grammatical perspective of language in general and IELTS speaking Part 3 in particular will enable them to convey the messages linguistically correct. Either awareness will yield to increase the score on the part of the examiners. This study has also implications for other large-scale proficiency tests like TOEFL and PTE. Further investigation for potential researchers in this realm would be taking speech acts into account for IELTS speaking Part 3. A second path of investigation would be considering the impact of pragmatics on part of IELTS speaking taking gender differences into account or raising IELTS/TOEFL candidates' grammatical and pragmatic awareness. Thirdly, it appears that there is no substantial body of literature accessible to identify the ability of learners to notice pragmatic features, such as the expression How about...? for suggestions in English as well as their proficiency level. To examine such an interrelationship, potential researches need to garner and compare data from learners with different proficiency levels in English language, for instance with an amalgamation of observational methods and self-report data. At last, taking all these aspects into account in further empirical and qualitative research design would give us permission to spread out our understanding of how pragmatics can be amalgamated in specific teaching contexts. Producing a particular pragmatic feature on the part of the learners, the researchers could have in-depth investigation of learners' pragmatic development by utilizing these ilk of methods through noticing their planning and thought processes (Tateyama, 2001). In the present study, pragmatic and grammatical awareness in the light of IELTS speaking Part 3 were adopted to garner data. As mentioned earlier, different methods might obtain different results. The researchers could painstakingly find a real IELTS Examiner in the same country to both administer and score IELTS speaking Part 3. Moreover, the researchers were not physically present on the venues of data collection process since they are Iranian.

Acknowledgement: The authors express their gratitude to the anonymous reviewers of the journal for their constructive comments.

\section{References}

Albertson, B. P. (2011). Facebook use and pragmatic/grammatical awareness among Japanese learners of English (Published master's thesis). Central Connecticut State University, New Britain.

Al-Hejin, B. (2005). Attention and awareness: Evidence from cognitive and second language acquisition research. Teachers College, Columbia University Working Papers in TESOL \& Applied Linguistics, 4(1), 1-22. https://doi.org/10.7916/D8668CQZ

Allami, H., \& Aghajari, J. (2014). Pragmatic knowledge assessment in listening sections of IELTS tests. Theory and Practice in Language Studies, 4(2), 332-340. doi:10.4304/tpls.4.2.332-340 
Andrews, S. (1999). All these like little name things: A comparative study of language teachers' explicit knowledge of grammar and grammatical terminology. Language Awareness, 8(3\&4), 143-159. doi:10.1080/09658419908667125

Askari, K., \& Langroudi, J. (2014). The effectiveness of Ur model in developing Iranian EFL learners' fluency and accuracy in speaking. Journal of Applied Linguistics and Language Research, 1(1), 75-86. http://www.jallr.com/index.php/JALLR/article/view/6/pdf 7

Austin, J. L. (1962). How to do things with words. Oxford: Oxford University Press.

Bachman, L. F, (1990). Fundamental considerations in language testing. Oxford: Oxford University Press

Bardovi-Harlig, K. (2001). Evaluating the empirical evidence: grounds for instruction in pragmatics? In: Rose, K. R., Kasper, G. (Eds.), pragmatics in in language teaching (pp.13-32.). Cambridge University Press, Cambridge, MA.

Bardovi-Harlig, K., \& Dornyei, Z. (1997). Pragmatic awareness and instructed L2 learning: an empirical investigation. Paper presented at the AAAL 1997Conference, Orlando.

Bardovi-Harlig, K., \& Dornyei, Z. (1998). Do language learners recognize pragmatic violations? Pragmatic versus grammatical awareness in instructed L2 learning. TESOL Quarterly, 32, 233-259. https://doi.org/10.2307/3587583

Bardovi-Harlig, K., \& Hartford, B. S. (1990). Congruence in native and nonnative conversations: Status balance in the academic advising session. Language Learning, 40, 467-501. https://doi.org/10.1111/j.14671770.1990.tb00603.x

Bardovi-Harlig, K., \& Hartford, B. S. (1991). Saying "No": Native and nonnative rejections in English. In L. F. Bouton \& Y. Kachru (Eds.), Pragmatics and language learning (Vol. 2, pp. 41-57). Urbana Champaign: University of Illinois at Urbana-Champaign, Division of English as an International Language.

Bardovi-Harlig, K., \& Hartford, B. (1993). Learning the rules of academic talk: A longitudinal study of pragmatic change. Studies in Second Language Acquisition, 15, 279-304. https://doi.org/10.1017/S0272263100012122

Bardovi-Harlig, K. (2000). Tense and aspect in second language acquisition: Form, meaning, and use. Language Learning: A Journal of Research in Language Studies, 50(Suppl. 1). https://eric.ed.gov/?id=ED445541

Bardovi-Harlig, K. \& Griffin, R. (2005). L2 pragmatic awareness: Evidence from the ESL classroom. System, 33, 401-415. doi:10.1016/j.system.2005.06.004

Bella, S. (2012). Pragmatic awareness in a second language setting: The case of L2 learners of Greek. Multilingua, 31(1), 133. doi:10.1515/mult.2012.001

Bloch, M. (1991). Language, Anthropology and Cognitive Science. Man (n.s.), 26(2), 183-198. doi: 10.2307/2803828 https://www.jstor.org/stable/2803828

Brown, P., \& Levinson, S. (1987). Politeness: Some universals in language usage. Cambridge, UK: Cambridge University Press.

Celce-Murcia, M., \& Olshtain, E. (2000). Discourse and context in language teaching. A guide for language teachers. Cambridge: Cambridge University Press.

Chomsky, N. (1965). Aspects of the theory of syntax. Cambridge, Mass.: MIT Press.

Cook, M., \& Liddicoat, A. J. (2002). The development of comprehension in interlanguage pragmatics: The case of request strategies in English. Australian Review of Applied Linguistics, 25(1), 19-39. https://doi.org/10.1075/aral.25.1

Doughty, C. (2003). Instructed SLA: Constraints, compensation, and enhancement. In Doughty and Long, The handbook of second language acquisition (pp. 256-310). Malden: Blackwell Publishing Ltd.

Goodenough, W. H. (1957). Cultural Anthropology and Linguistics. In P. L. Garvin (Ed.), Report of the Seventh Round Table Meeting on Linguistics and Language Study. Washington, DC: Georgetown University Press. 
Holmes, J. (2008). An introduction to sociolinguistics. Harlow: Pearson Education limited.

Hou, K., \& Na-Thalang, S. S. (2013). The role of grammar awareness in learning English wh-movement by Chinese L2 learners. English Language and Literature Studies, 3(3), 56-68. doi:10.5539/ells.v3n3p56

Hymes, D. (1972). On communicative competence. In Pride, J. B. \& Holmes, J. (Eds.), Sociolinguistics (pp. 269-293). Harmondsworth: Penguin.

Jahan, A., \& Kormos, J. (2015). The impact of textual enhancement on EFL learners' grammatical awareness of future plans and intentions. International Journal of Applied Linguistics, 25(1), 46-66. doi: 10.1111/ijal.12049

Jung, J. Y. (2001). Issues in acquisitional pragmatics. Working paper in TESOL \& Applied Linguistics, 2(3), 1-13. doi: 10.7916/salt.v2i3.1642

Jung, J. Y. (2002). Issues in acquisitional pragmatics. Working Paper in TESOL and Applied Linguistics, 2(3), 1-13. https://doi.org/10.7916/D84F237W

Juul, H. (2005). Grammatical awareness and the spelling of inflectional morphemes in Danish. International Journal of Applied Linguistics, 15(1), 87-112. https://doi.org/10.1111/j.1473-4192.2005.00082.x

Karbalaei, A., \& Rahmanzade, M. K. (2015). An investigation into pragmatic knowledge in the reading section of TOLIM, TOEFL, and IELTS examinations. English language teaching, 8(5), $208-221$. doi:10.5539/elt.v8n5p208

Kashiwagi, K., \& Ito, Y. (2017). EFL learners' grammatical awareness through accumulating formulaic sequences of morphological structure (-ing). English Language Teaching, 10(11), 60-75. doi: 10.5539/elt.v10n11p60

Kennedy, S. (2012). Exploring the relationship between language awareness and second language use. TESOL Quarterly, 46(2), 398-408. http://dx.doi.org/10.1002/tesq.24

Kirschner, P. A., Sweller, J., \& Clark, R. E. (2006). Why minimal guidance during instruction does not work: an analysis of the failure of constructivist, discovery, problem-based, experiential, and inquiry-based teaching. Educational Psychologist, 4(1) 75-86. doi:10.1207/s15326985ep4102_1

Kumaravadivelu, B. (2006). Understanding language teaching: From method to postmenthod. Mahwah, NJ: Lawrence Erlbaum.

Lakoff, R. (1973). The logic of politeness: Or minding your p's and q's. Chicago Linguistic Society, 9, 292-305.

Lee, W. T. (2009). EFL learners' pragmatic awareness: an analysis of four-university students in Taiwan. Journal of China Institute of Technology, 40(6), 629-652. http://aca.cust.edu.tw/pub/journal/40/40-38.pdf

Leech, G. (1983). Principles of pragmatics. London: Longman.

Matsumura, S. (2001). Learning the rules for offering advice: A quantitative approach to second language socialization. Language Learning, 51(4), 635-679. http://dx.doi.org/10.1111/0023-8333.00170.

Matsumura, S. (2003). Modelling the relationships among interlanguage pragmatic development, L2 proficiency, and exposure to L2. Applied Linguistics, 24(4), 465-491. http://dx.doi.org/10.1093/applin/24.4.465.

Memarzadeh, A. (2008). IELTS maximiser educational book. Tehran: Koroush.

Nunan, D. (2003). Designing tasks for the communicative classroom. Cambridge: Cambridge University Press.

Omar, A. S. (1991). How learners greet in Kiswahili. In L. Bouton \& Y. Kachru (Eds.), Pragmatics and language learning (Vol. 2, pp. 59-73). Urbana-Champaign: University of Illinois, Division of English as an International Language.

Omar, A. S. (1992). Opening and closing conversations in Kiswahili: A study of the performance of native speakers and learners. Unpublished doctoral dissertation, Indiana University, Bloomington.

Pallant, J. (2013). SPSS survival manual: a step by step guide to data analysis using SPSS. Buckinghum: Open University Press. 
Quinn, N., \& Holland, D. (1987). Culture and cognition. In D. Holland \& N. Quinn (Eds.), Cultural models in language and thought (p. 1-40). Cambridge University Press.

Rafieyan, V., Sharafi-Nejad, M., Damavand, A., Lin, S. E., \& Abdul-Rashid, M. (2014). Relationship between emotional intelligence and pragmatic awareness. International Journal of Applied Linguistics \& English Literature, 3(4), 143-149. http://dx.doi.org/10.7575/aiac.ijalel.v.3n.4p.143

Rafieyan, V., Sharafi-Nejad, M., \& Eng, L. S. (2014). Effect of pragmatic awareness on comprehension and production of conventional expressions. Theory and practice in language studies, 4(7), 1352-1358. doi:10.4304/tpls.4.7.1352-1358

Rezaei, A. A., \& Hosseinpur, R. M. (2011). On the role of consciousness-raising tasks in learning grammar. The Iranian EFL Journal, 39(3), 237.

Robinson, P. (1997). Generalizability and automaticity of second language learning under implicit, incidental, enhanced, and instructed conditions. Studies in Second Language Acquisition, 19, 223-247. https://doi.org/10.1017/S0272263197002052

Rose, K., \& Kwai-Fun, C. G. (2001). Inductive and deductive teaching of compliments and compliment responses. In: Rose, K., Kasper, G. (Eds.), Pragmatics in language teaching (pp. 145-170.). Cambridge: Cambridge University Press.

Rose, K. R., \& Ng, C. K. (2001). Inductive and deductive teaching of compliments and compliment responses. In: Rose, K. R., Kasper, G. (Eds.), Pragmatics in language teaching. Cambridge University Press, Cambridge, MA, pp. 145-170.

Schauer. G. A. (2006). Pragmatic awareness in ESL and EFL contexts: Contrast and development. Language Learning, 56(2), 269-318. https://doi.org/10.1111/j.0023-8333.2006.00348.x

Schmidt, R. (1993). Consciousness, learning and interlanguage pragmatics. In G. Kasper \& S. Blum-Kulka (Eds.), Interlanguage pragmatics (p. 21-42). New York: Oxford University Press.

Schmidt, R. (1995). Consciousness and foreign language learning: A tutorial on the role of attention and awareness in learning. In R. Schmidt (Ed.), Attention and awareness in foreign language learning (Technical Report 9, pp. 1-63). Honolulu: University of Hawai'i, Second Language Teaching and Curriculum Center.

Schmidt, R. W. (2001). Attention. In P. Robinson (Ed.), Cognition and Second Language Instruction (pp. 3-32). Cambridge: Cambridge University Press.

Schmidt, R. (2012). Attention, awareness, and individual differences in language learning. Perspectives on Individual Characteristics and Foreign Language Education, 6, 27. http://dx.doi.org/10.1515/9781614510932.27

Searle, J. R. (1969). Speech acts: An essay in the philosophy of language. Cambridge: Cambridge University Press.

Shohamy, E. (2015). Predicting speaking proficiency from cloze tests: theoretical and practical considerations for tests substitution. Applied linguistics, 3(2), 161-171. https://doi.org/10.1093/applin/III.2.161

Sorour, N. (2015). Grammatical versus pragmatic awareness: the case of Egyptian students in an English-medium university. (Published Master thesis). The American University in Cairo: Egypt.

Svalberg, A. M. L. (2007). Language awareness and language learning. Language Teaching, 40(04), 287-308. http://dx.doi.org/10.1017/S0261444807004491

Takahashi, S. (2001). The role of input enhancement in developing pragmatic competence. In: K.R. Rose, \& G. Kasper, (Eds.), Pragmatics in language teaching (pp. 171-199). Cambridge: Cambridge University Press.

Takahashi, S. (2005). Noticing in task performance and learning outcomes: A qualitative analysis of instructional effects in interlanguage pragmatics. System, 33(3), 437-461. http://dx.doi.org/10.1016/j.system.2005.06.006

Takahashi, S. (2013). The encyclopedia of applied linguistics. Oxford: Blackwell.

Tateyama, Y. (2001). Explicit and implicit teaching of pragmatic routines. In K. Rose \& G. Kasper (Eds.), Pragmatics in language teaching (pp.200-222). Cambridge: Cambridge University Press. 
Thomas, J. (1983). Cross-cultural pragmatic failure. Applied Linguistics, 4(2), 91-112. doi: 10.1093/applin/4.2.91 Wardhaugh, R. (2008). An introduction to sociolinguistics. Oxford: Blackwell. Watts.

Yule, G. (2000). Pragmatics. Oxford: Oxford University Press.

Yule, G., \& Brown, G. (1989). Discourse analysis. Cambridge: Cambridge University Press. 


\section{Appendix 1}

\section{Test of Pragmatic/Grammatical Awareness}

\section{Instructions}

Thank you for helping with this research project. Below you will see 25 short conversations between Peter and Anna. Their English will sometimes be correct but will sometimes have a problem. Your job is to decide how good their English is and decide if the bold part is appropriate/correct or not. Please see the following example:

Peter: Let's go eat! Anna: No.

Is the bold part appropriate/correct?

If there was a problem, how bad do you think it was?

$\begin{array}{lll}\square & \square & \text { Not bad at all } \square \square \square \square \square \text { Very bad } \\ \text { Yes } \quad \text { No } & \end{array}$

Anna's answer is very strange and rude. So we should put an $\mathrm{X}$ in the box marked No. After this, you decide how big the mistake is. Put an X in one of the boxes between "not bad at all" and "very bad." For a small mistake, mark the second or third box; for a serious mistake mark the last box.

Remember: This is not a test; I am interested in what you think!

\section{Conversations}

1. Peter is inviting Anna to a party.

P: Hey, do you want to come to a party this weekend?

\section{A: I'm kind of busy, but if I have free time I come.}

Is the bold part appropriate/correct?

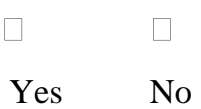

2. Anna is asking about Peter's trip to Canada.
If there was a problem, how bad do you think it was?

$$
\text { Not bad at all } \square \square \square \square \square \text { Very bad }
$$

A: So how was your trip to Canada? It seems like you had fun!

\section{P: Actually it was terrible! I am sick the whole time!}

Is the bold part appropriate/correct?

Yes No

3. Peter invites Anna to his house.

P: Don't you want to come to my house tonight?

A: Sure! Want me to bring anything?

Is the bold part appropriate/correct?

Yes No

4. Anna offers Peter something to drink.
If there was a problem, how bad do you think it was?

$$
\text { Not bad at all } \square \square \square \square \square \text { Very bad }
$$


A: Peter, do you want something to drink?

P: Never, I'm a huge trouble for you.

Is the bold part appropriate/correct?

If there was a problem, how bad do you think it was?

$$
\text { Not bad at all } \square \square \square \square \square \text { Very bad }
$$

$$
\text { Yes No }
$$

5. Peter and Anna are making plans for the weekend.

P: What are your plans for this weekend?

\section{A: I might go hiking. Would you like to come?}

Is the bold part appropriate/correct?

Yes

$$
\text { No }
$$

6. Peter is asking Anna to lend him a book.

\section{P: Can I borrowing that book when you are finished?}

A: Sure, no problem.

Is the bold part appropriate/correct?

If there was a problem, how bad do you think it was?
If there was a problem, how bad do you think it was?

Not bad at all $\square \square \square \square \square$ Very bad

$$
\text { Not bad at all } \square \square \square \square \square \text { Very bad }
$$ \\ Yes No}

7. Peter is complimenting Anna about a picture she took.

P: Wow, this picture is so beautiful!

A: You're complimenting me!

Is the bold part appropriate/correct?

If there was a problem, how bad do you think it was?

\section{Not bad at all $\square \square \square \square \square$ Very bad}

$$
\text { Yes No }
$$

8. Anna is inviting Peter to drink coffee together and talk.

A: Hey, do you want to have a cup of coffee with me and talk?

P: Excuse me, I have too much homework today.

Is the bold part appropriate/correct?

$$
\text { Yes No }
$$

9. Peter is talking to Anna about a movie they saw.

P: I love that movie! It's awesome!
If there was a problem, how bad do you think it was?

\section{Not bad at all $\square \square \square \square \square$ Very bad}




\section{A: Really? I don't think it's that good. What you liked about it?}

Is the bold part appropriate/correct?

If there was a problem, how bad do you think it was?

Not bad at all $\square \square \square \square \square$ Very bad

$$
\text { Yes No }
$$

10. Anna and Peter are talking about the weather.

A: This weather is too hot!

P: Excuse me, I think this weather is nice.

Is the bold part appropriate/correct?

If there was a problem, how bad do you think it was?

Not bad at all $\square \square \square \square \square$ Very bad

Yes $\quad$ No

11. Anna is talking to Peter, who she has recently met.

A: Nice to meet you, Peter. We'd better be friends.

P: Nice meeting you too.

Is the bold part appropriate/correct?

Yes No

12. Peter offers Anna a hamburger.

P: Hey Anna, do you want a hamburger?

A: No thanks. I don't really like the hamburger.

Is the bold part appropriate/correct?

Yes No

13. Anna is asking her friend Peter to help her fix her bicycle.

\section{A: Hi Peter! You'll help me fix my bicycle this weekend, OK?}

P: Sure, Just give me a call on Saturday or Sunday.

Is the bold part appropriate/correct?

$\begin{array}{cc}\square & \square \\ \text { Yes } & \text { No }\end{array}$

14. Anna sees a picture of Peter.

A: Peter, you look so cool in this picture! 


\section{P: Thanks! I was in Brazil.}

Is the bold part appropriate/correct?

If there was a problem, how bad do you think it was?

Not bad at all $\square \square \square \square \square$ Very bad

$$
\text { Yes No }
$$

15. Peter just heard Anna sing in a school performance.

P: I can't believe how well you sing! Your voice was amazing!

\section{A: I'm not thinking it's that great, but thanks anyway!}

Is the bold part appropriate/correct?

If there was a problem, how bad do you think it was?

Not bad at all $\square \square \square \square \square$ Very bad

$$
\text { Yes No }
$$

16. Peter invites Anna to see a movie.

\section{P: You may want to see a movie with me tomorrow night.}

A: Sure, what time?

Is the bold part appropriate/correct?

Yes No

17. Peter offers to help Anna with her homework.

P: Hey, do you need some help with that assignment?

\section{A: Sure, would you mind?}

Is the bold part appropriate/correct?

$\square$
Yes $\quad \square$

18. Peter asks if Anna is able to come to New York.

\section{P: Hey! Can you coming to New York with me this weekend?}

A: Sorry, I don't think I'll have free time.

Is the bold part appropriate/correct?

If there was a problem, how bad do you think it was?

$$
\text { Not bad at all } \square \square \square \square \square \text { Very bad }
$$

\section{Not bad at all $\square \square \square \square \square$ Very bad}


Is the bold part appropriate/correct?

Yes $\quad$ No

20. Anna and Peter are talking about a song.

A: I love Lady Gaga's new song!

\section{P: I disagree with you and don't like that song.}

Is the bold part appropriate/correct?

Yes $\quad$ No

21. Anna and Peter are having some soup at a restaurant.

A: This soup is delicious.

P: Really? I think it's a little too salty.

Is the bold part appropriate/correct?

If there was a problem, how bad do you think it was?

Not bad at all $\square \square \square \square \square$ Very bad
If there was a problem, how bad do you think it was?

$$
\text { Not bad at all } \square \square \square \square \square \text { Very bad }
$$

If there was a problem, how bad do you think it was?

$$
\text { Not bad at all } \square \square \square \square \square \text { Very bad }
$$

$\begin{array}{lll}\square & \square & \text { Not bad at all } \square \square \square \square \square \text { Very bad } \\ \text { Yes } \quad \text { No } & \end{array}$

22. Anna is complimenting Peter on a dinner he cooked.

A: Peter, the dinner you made was delicious!

P: Thanks! I'm happy that you like.

Is the bold part appropriate/correct? If there was a problem, how bad do you think it was?

$$
\text { Not bad at all } \square \square \square \square \square \text { Very bad }
$$

$$
\text { Yes No }
$$

23. Peter asks Anna about plans for the summer.

P: What should I do during my summer vacation?

\section{A: Do you want to travelling to Spain with me?}

Is the bold part appropriate/correct?

Yes $\quad$ No

24. Peter is commenting on Anna's resume picture.

P: Wow, you look so professional in this picture!

A: Your saying makes me happy.

Is the bold part appropriate/correct?

If there was a problem, how bad do you think it was? 


$\begin{array}{cc}\square & \square \\ \text { Yes } & \text { No }\end{array}$

Not bad at all $\square \square \square \square \square$ Very bad

25. Anna is inviting Peter to the mall.

A: Hey, want to come to the mall with us?

P: Sorry, I'm a little busy now. Maybe another time.

Is the bold part appropriate/correct?

Yes
If there was a problem, how bad do you think it was?

Not bad at all $\square \square \square \square \square$ Very bad 